Published in final edited form as:

Inorg Chem. 2007 June 11; 46(12): 4989-4996. doi:10.1021/ic0702441.

\title{
Sulfur K-edge XAS and DFT Studies on Nill Complexes with Oxidized Thiolate Ligands: Implications for the Roles of Oxidized Thiolates in the Active Sites of Fe and Co Nitrile Hydratase
}

\author{
Abhishek Dey ${ }^{+}$, Stephen P. Jeffrey $\#$, Marcetta Darensbourg ${ }^{*}$, Keith O. Hodgson ${ }^{+, \pm^{*}}$, Britt \\ Hedman $^{ \pm^{*}}$, and Edward I. Solomon ${ }^{+, \pm^{*}}$ \\ +Department of Chemistry, Stanford University, Stanford, CA, 94305 \\ \#Department of Chemistry, Texas A\&M University, College Station, TX, 77843 \\ \pm Stanford Synchrotron Radiation Laboratory, SLAC, Stanford University, Menlo Park, California 94025
}

\begin{abstract}
$\mathrm{S}$ K-edge XAS data on a series of $\mathrm{Ni}^{\mathrm{II}}$ complexes with thiolate $\left(\mathrm{RS}^{-}\right)$and oxidized thiolate $\left(\mathrm{RSO}_{2}{ }^{-}\right)$ligands are used to quantify Ni-S bond covalency and its change upon ligand oxidation. Analyses of these results using geometry optimized DFT calculations suggest that the Ni-S $\sigma$ bonds do not weaken on ligand oxidation. Molecular orbital analysis indicates that these oxidized thiolate ligands use filled high lying S-O $\pi^{*}$ orbitals for strong $\sigma$ donation. However, the $\mathrm{RSO}_{2}{ }^{-}$ligands are poor $\pi$ donors as the orbital required for $\pi$ interaction is is used in the $\mathrm{S}-\mathrm{O} \sigma$ bond formation. The oxidation of the thiolate reduces the repulsion between electrons in the filled $\mathrm{Ni}_{2}$ orbital and the thiolate out of plane $\pi$-donor orbital leading to shorter Ni-S bond length relative to a thiolate donor. The insights obtained from these results are relevant to the active sites of Fe and Co type nitrile hydratases (Nhase) that also have oxidized thiolate ligands. DFT calculations on models of the active site indicate that while the oxidation of these thiolates has a major effect in the axial ligand binding affinity of the Fe type Nhase (where there is both $\sigma$ and $\pi$ donation from the S ligands), it has only a limited effect on the sixth ligand binding affinity of the Co type Nhases (where there is only $\sigma$ donation). These oxidized residues may also play a role in substrate binding and proton shuttling at the active site.
\end{abstract}

\section{Keywords}

S K-edge XAS; DFT; H-bonding; Ni-thiolate; Nitrile Hydratase

\section{Introduction}

Cysteine based oxidized thiolate ligands (e.g. $\mathrm{CysSO}_{2}{ }^{-}, \mathrm{CysSO}^{-}$) in contiguous CysteineSerine-Cysteine, CSC, ligation have been found in nature in the active sites of $\mathrm{Fe}^{\mathrm{III}}$ and $\mathrm{Co}$ III dependent nitrile hydratases (Nhase). ${ }^{1,2}$ These enzymes are key components in bioremediation of common plant metabolism byproducts. ${ }^{3}$ The oxidation of these thiolates results from a post-translational modification upon exposure to dioxygen. ${ }^{4}$ As the unoxidized active site of Fe type Nhase is inactive, it is surmised that these oxidized thiolate ligands are key to reactivity. 5 
The role of the oxidized thiolate ligands in the active site of Nhase has received a great deal of attention particularly for the Fe enzyme. Several model complexes have been synthesized that mimic the first co-ordination sphere of these enzymes including the S-coordinated, Soxygenated ligands. ${ }^{6-9}$ In general there models lack the highly conserved H-bonding interactions from the protonated arginine residues to the negatively charge oxygen atoms of the $\mathrm{RSO}_{\mathrm{x}}$ units (one to each unit) present at the active site. ${ }^{10}$ Mutation of these residues leads to inactivation of the enzyme and they are proposed to be the source of protons during the reaction. ${ }^{11,12}$ These studies have been complemented by spectroscopic and computational results that have focused on the electronic structure of the transition metal active site. $8,13,14$ Through such studies a general consensus has been reached that these oxidized thiolate ligands are weak donors and hence they increase the Lewis acidity of these active sites. 7,15

A large number of $\mathrm{Ni}^{\mathrm{II}}$ complexes have been reported having a diamino-dithiolato coordination sphere where the thiolate has been systematically oxidized to $\mathrm{RSO}^{-}$and $\mathrm{RSO}_{2}^{-}$. 16-20 The crystallographically characterized complexes show that the Ni-S bond lengths decrease from 2.17 to $2.13 \AA$ upon oxidizing $\mathrm{RS}^{-}$to $\mathrm{RSO}_{2}{ }^{-}{ }^{17}$ Square planar $\mathrm{Ni}^{\mathrm{II}}$ complexes generally form only $\sigma$ bonds due to the low-spin $\mathrm{d}^{8}$ configuration. Shortening of a M-S bond length upon oxidation of a $\mathrm{RS}^{-}$to $\mathrm{RSO}_{2}^{-}$(by $0.04 \AA$ ) has also been observed for 6 co-ordinate low-spin Co $\mathrm{Co}^{\mathrm{III}}$ complexes which is low-spin $\mathrm{d}^{6}$ and also allow for only $\sigma$ interactions with these ligands. ${ }^{21}$ The shorter M-S bond length of an oxidized thiolate is an apparent contradiction to the general idea that the $\mathrm{S}$ donor strength decreases upon oxidation. Thus a quantitative experimental estimate of the change in M-S bond covalency upon oxidation is required to elucidate the nature of bonding from the oxidized thiolate donors.

Ligand K-edge X-ray absorption spectroscopy (XAS) is a direct probe of ligand-metal bond covalency. 22,23 The K-edge spectra of transition metal complexes have an intense low energy pre-edge feature that is assigned as a ligand $1 \mathrm{~s}\left(\mathrm{~L}_{1 \mathrm{~s}}\right)$ to metal $3 \mathrm{~d}\left(\mathrm{M}_{3 \mathrm{~d}}\right)$ transition. The pre-edge transition energy has contributions mainly from the $Z_{\text {eff }}$ of the metal, its ligand field and the charge on the ligand. While the first two determine the energy of the acceptor $\mathrm{M}_{3 \mathrm{~d}}$ orbital, the later governs the energy of the donor ligand 1s orbital. The intensity (I) of this transition is given by:

$$
\mathrm{I}\left(\mathrm{L}_{1 \mathrm{~s}} \rightarrow \mathrm{M}_{3 \mathrm{~d}}\right)=\alpha^{2} \mathrm{I}\left(\mathrm{L}_{1 \mathrm{~s}} \rightarrow \mathrm{L}_{\mathrm{np}}\right)
$$

Where $\alpha$ is the ligand co-efficient in the acceptor orbital wavefunction and $\mathrm{I}\left(\mathrm{L}_{1 \mathrm{~s}} \rightarrow \mathrm{L}_{\mathrm{np}}\right)$ is the transition moment integral or the intensity of a purely ligand based $1 \mathrm{~s} \rightarrow \mathrm{np}$ transition, which depends primarily on the $Z_{\text {eff }}$ of the ligand. ${ }^{24,25}$ The pure $1 \mathrm{~s} \rightarrow 3$ p dipole moment integral for a thiolate ligand $\left(\mathrm{RS}^{-}\right)$was initially estimated from the pre-edge intensity of plastocyanin and recently slightly modified from an increased data set. ${ }^{24,26}$ The pre-edge intensity thus provides a direct estimate of ligand-metal bond covalency $\left(\alpha^{2}\right)$. The K-edge XAS of a thiolate based ligand has additional higher energy features that are assigned as $\mathrm{S}_{1 \mathrm{~s}} \rightarrow \mathrm{RS}_{\mathrm{C}-\mathrm{S} \sigma^{*}}$ transitions, which are a direct probe of the $Z_{\text {eff }}$ on the ligand and thus show strong correlation to the oxidation state of the ligand. ${ }^{23,27}$ These features have been used to identify the oxidation states of the oxidized thiolates of the active form of Fe-type Nhase in solution. ${ }^{13}$

This technique has recently been used to understand the effect of ligand oxidation on a lowspin $\mathrm{Fe}^{\mathrm{III}}$ system where one of the two thiolate ligand of the parent complex is oxidized to SO. ${ }^{28}$ Upon oxidation, the Fe-S distances of the oxidized thiolate elongates and that of the remaining unoxidized thiolate decreases relative to the parent Fe-S thiolate distances. The changes observed in the S K-edge spectra reflect a large decrease in $\pi$ donation of an oxidized thiolate relative to a thiolate. However, the effect of thiolate oxidation on the $\sigma$ donation could not be quantified as the $\mathrm{S}_{1 \mathrm{~s}}$ orbital of these ligands is shifted to deeper energy which in turn raises the pre-edge $\mathrm{S}_{1 \mathrm{~s}} \rightarrow \mathrm{Fe}_{3 \mathrm{~d}}$ transition energy such that it overlaps the rising edge features from the unoxidized thiolate. 28 
In this study we use sulfur K-edge XAS on a series of $\mathrm{Ni}^{\mathrm{II}}$ complexes based on the $\mathrm{N}, \mathrm{N}$ '-bis (2-mercaptoethyl)-1,5-diazacyclootanato (DACO) ligand system (Fig. 1). The thiolates have been systematically oxidized to $\mathrm{RSO}_{2}{ }^{-}$, which provides an opportunity to experimentally probe the effect of thiolate oxidation on Ni-S $\sigma$ bond covalency. Our results indicate that the Ni-S bond of an oxidized thiolate is as covalent as that of an unoxidized thiolate. DFT calculations are used to develop a bonding description and to understand the covalency of the oxidized thiolate-sulfur-Ni bonds. These complexes model the mixed ligand environment present in the first coordination sphere of Nhase (Fig. 1, right). We then use DFT calculations to explore the role of thiolate oxidations on the electronic structure and substrate binding affinity of $\mathrm{Fe}$ and Co type Nhases.

\section{Experimental Details}

\section{Materials and Methods}

The complexes $\mathrm{Ni}^{\mathrm{II}}\left[\mathrm{N}, \mathrm{N}^{\prime}\right.$-bis(2-mercaptoethyl)-1,5-diazacyclooctanato] $\mathrm{Ni}(\mathrm{DACO})$, $\mathrm{Ni}{ }^{\mathrm{II}}\left[\mathrm{N}, \mathrm{N}\right.$-2-mercaptoethyl, 2-sulfinatoethyl-1,5-diazacyclootanato] $\mathrm{Ni}(\mathrm{MSE})$ and $\mathrm{Ni}^{\mathrm{II}}[\mathrm{N}, \mathrm{N}$ bis(2-sulfinatoethyl)-1,5-diazacyclooctanato] $\mathrm{Ni}(\mathrm{BSE})$ were synthesized according to literature. ${ }^{17,29}$ For XAS experiments the samples were ground into a fine powder and dispersed as thinly as possible on sulfur-free Mylar tape. This procedure has been verified to minimize self-absorption effects. ${ }^{27}$ The sample was then mounted across the window of an aluminum plate.

\section{Data Collection}

XAS data were measured at the Stanford Synchrotron Radiation Laboratory using the 54-pole wiggler beam line 6-2. Details of the experimental configuration for low energy studies have been described previously. The energy calibration, data reduction and error analysis follow the methods described in Reference 24.

\section{Fitting Procedures}

Pre-edge features were fit by pseudo-Voigt line shapes (sums of Lorentzian and Gaussian functions) using EDG_FIT. ${ }^{30}$ This line shape is appropriate as the experimental features are expected to be a convolution of a Lorentzian transition envelope and a Gaussian line shape imposed by the beam line optics. ${ }^{31,32}$ A fixed 1:1 ratio of Lorentzian-to-Gaussian contribution successfully reproduced the pre-edge features. The rising edges were also fit with pseudo-Voigt line shapes. Fitting requirements included reproducing the data and its second derivative, using the minimum number of peaks. In this case we find that one peak was sufficient. The intensity of a pre-edge feature (peak area) is obtained from the product of peak height and full width at half maxima of the pseudo-Voigt peaks which were needed to successfully fit the feature in a given fit. The reported intensity values for the model complexes are an average of all of the accepted pre-edge fits, typically 5-6 (which differed from each other by less than 3\%). The fitted intensities were converted to $\% \mathrm{~S}_{3 \mathrm{p}}$ character using the pre-edge feature of plastocyanin as a reference (where 1.01 units of intensity, obtained using EDG_FIT, corresponded to 38\% $\mathrm{S}_{3 \mathrm{p}}$ character).

\section{DFT Calculations}

All calculations were performed on dual-CPU Pentium Xeon $2.8 \mathrm{GHz}$ work stations. Geometry optimizations for the Ni complexes were performed using the Amsterdam Density Functional (ADF) program, versions 2004.01 and developed by Baerends et al ${ }^{33}$ A triple- $\zeta$ Slater-type orbital basis set (ADF basis set TZP) with a single polarization function at the local density approximation of VoskoWilk, and Nusair, ${ }^{34}$ with nonlocal gradient corrections of Becke ${ }^{35}$ and Perdew ${ }^{36}$ were employed. For the Co and Fe Nhase active sites the geometries were 
optimized in Gaussian $03^{37}$ using BP86 ${ }^{38}$ functional and a mixed basis set $(6-311 \mathrm{~g} *$ on Fe, $\mathrm{Co}, \mathrm{S}, \mathrm{N}$ and 6-31g* on $\mathrm{O}, \mathrm{C}, \mathrm{H}$ ). All single point calculations were performed using the BP86 functional and a $6-311+\mathrm{g}^{*}$ basis set in Gaussian 03 . The molecular orbitals were plotted using Molden ver 4.1 and the Mulliken ${ }^{39}$ population analyses were performed using the PyMOlyze program. .0

\section{Results and Analysis}

\subsection{Ni-S bond covalency: XAS}

The $\mathrm{S}$ K-edge XAS of Ni(DACO) is shown in Fig. 2 (black). The spectrum has a sharp feature at $2470.8 \mathrm{eV}$ (Table 1) which is assigned to the $\mathrm{RS}_{1 \mathrm{~s}} \rightarrow \mathrm{Ni}_{3 \mathrm{~d}}$ pre-edge transition. The intensity of the pre-edge transition is directly proportional to the $\mathrm{S}_{3 \mathrm{p}}$ mixing in the acceptor $\mathrm{Ni}_{3 \mathrm{~d}} \mathrm{LUMO}$ of these sq. planar $\mathrm{Ni}^{\mathrm{II}}$ complexes; i.e. $\mathrm{Ni}-\mathrm{S}$ bond covalency. The pre-edge intensity is obtained from fits to the experimental data to be 1.25 units. This intensity translates to $46 \% \mathrm{~S}_{3 \mathrm{p}}$ character in the acceptor $\mathrm{Ni}_{3 \mathrm{~d}}$ orbital (Table 1) using thiolate as a reference. Note that this is a sum total contribution from two thiolates i.e. the contribution from individual thiolates to the $\mathrm{Ni}_{3 \mathrm{~d}} \mathrm{LUMO}$ is $23 \%$. There is another transition (rising-edge) at $2473.0 \mathrm{eV}$ (Table 1) which is assigned to the $\mathrm{RS}_{1 \mathrm{~s}} \rightarrow \mathrm{RS}_{\mathrm{C}-\mathrm{S} \sigma^{*}}$ transition and it is indicative of the oxidation state of the $\mathrm{S}$ atom.

The S K-edge XAS of Ni(MSE) (thiolate donor oxidized to $\mathrm{RSO}_{2}^{-}$, red, Fig. 2) has the preedge and the rising edge transitions of the unoxidized thiolate ligand at $2470.7 \mathrm{eV}$ and 2473.1 $\mathrm{eV}$, respectively, (Table 1) which are at the same energy and approximately half as intense as those in $\mathrm{Ni}(\mathrm{DACO})$. This reflects the fact that $\mathrm{Ni}(\mathrm{MSE})$ has one $\mathrm{RS}^{-}$donor relative to two in $\mathrm{Ni}(\mathrm{DACO})$. The $\mathrm{RSO}_{2}{ }^{-}{ }_{1 \mathrm{~s}} \rightarrow \mathrm{Ni}_{3 \mathrm{~d}}$ and the $\mathrm{RSO}_{2}{ }_{1 \mathrm{~s}} \rightarrow \mathrm{RSO}_{2}{ }^{-} \mathrm{C}-\mathrm{S} \sigma^{*}+\mathrm{S}-\mathrm{O} \sigma^{*}$ transitions are observed at $2476.1 \mathrm{eV}$ and $2478.2 \mathrm{eV}$ (Table 1), respectively. Due to the overlap of the preedge feature of $\mathrm{RSO}_{2}{ }^{-}$with the rising edge of the $\mathrm{RS}^{-}$, it is not possible to obtain unambiguous estimates of the pre-edge intensity for the $\mathrm{RSO}_{2}{ }^{-}$ligand of this complex. However, these transitions are clearly visible in the $\mathrm{S}$ K-edge XAS spectrum of the Ni(BSE) complex (blue, Fig. 2) where both thiolate ligands are oxidized to $\mathrm{RSO}_{2}{ }^{-}$. Both the pre-edge and the rising edge features are shifted up by $\sim 5 \mathrm{eV}$ relative to the corresponding $\mathrm{RS}^{-}$transitions, reflecting the stabilization of the $\mathrm{S}_{1 \mathrm{~s}}$ orbitals in the $\mathrm{RSO}_{2}{ }^{-}$ligand upon oxidation. The intensity of this pre-edge transition is obtained from fits to the data to be 1.37 units. Note that this intensity can not be directly converted to $\% \mathrm{~S}_{3 \mathrm{p}}$ mixing in the acceptor $\mathrm{Ni}_{3 \mathrm{~d}}$ orbital as, I (transition moment integral) in equation 1 increases with $Z_{\text {eff }}$ and there is no well defined reference allowing estimation of the transition dipole integral for an oxidized $\mathrm{RSO}_{2}{ }^{-}$donor. However, I was found to increase linearly with increase in the relative $1 \mathrm{~s}$ orbital energies of the different sulfur-based donors. $25,41,42$ Note that the relative $S_{1 \mathrm{~s}}$ orbital energies can not be obtained from the risingedges of the free ligands as the acceptor orbitals (e.g. C-S $\sigma^{*}$ in thiolate vs C-S $\sigma^{*}$ and $\mathrm{S}-\mathrm{O}$ $\sigma^{*}$ in $\mathrm{RSO}_{2}{ }^{-}$etc) of these ligands are at different energies.

The relative 1s orbital energies for the $\mathrm{RS}^{-}$and the $\mathrm{RSO}_{2}{ }^{-}$ligands can be accurately obtained from their relative pre-edge energies in the $\mathrm{S}$ K-edge XAS of Ni(MSE). This is because these involve transitions from the two different $\mathrm{S}$ based donors to the same $\mathrm{Ni}_{3 \mathrm{~d}}$ acceptor orbital. Thus the relative pre-edge energies of $\mathrm{RS}^{-}$and $\mathrm{RSO}_{2}{ }^{-}$at $2470.7 \mathrm{eV}$ and $2476.1 \mathrm{eV}$, respectively, imply a $5.4 \mathrm{eV}$ difference in the $1 \mathrm{~s}$ orbital energy of these ligands. Using this 5.4 $\mathrm{eV}$ shift and the linear relation between the 1s orbital energy and dipole integral $\left.\left(<_{1 \mathrm{~s}}|\mathbf{r}| \mathrm{S}_{3 \mathrm{p}}\right\rangle\right)$ 41,42 its value for $\mathrm{RSO}_{2}{ }^{-}$is estimated to be 18.2 (the value for thiolate is 8.05). ${ }^{41,43}$ The total intensity under the pre-edge of $\mathrm{Ni}(\mathrm{BSE})$ is 1.09 units which corresponds to $18 \% \mathrm{~S}_{3 \mathrm{p}}$ character (Table 1) in the acceptor $\mathrm{Ni}_{3 \mathrm{~d}}$ orbital in $\mathrm{Ni}$ (BSE). This is an apparent decrease from the $46 \%$ of $\mathrm{Ni}(\mathrm{DACO})$ even though the $\mathrm{Ni}-\mathrm{S}$ bond length decreases upon oxidation. Note that this is the first time that a direct experimental estimate of covalency of a $\mathrm{RSO}_{2}{ }^{-}$ligand has been obtained. 


\subsection{Ni-S bond covalency: DFT calculations}

Geometry optimized DFT calculations were used to obtain a description of the ground state electronic structure of these complexes to gain insight into the changes in bonding that occur upon $\mathrm{S}$ oxidation. The calculated Ni-S bond lengths are in good agreement with the reported crystal structures of these complexes while the Ni-N bond lengths are $\sim 0.06 \AA$ longer (Table 2). Note that the optimized Ni-S bonds in $\mathrm{Ni}(\mathrm{BSE})(2.13 \AA)$ are $0.04 \AA$ shorter than the Ni-S bonds in $\mathrm{Ni}$ (DACO) $\left(2.17 \AA\right.$ ) reproducing the trend observed in the crystal structures. ${ }^{17}$ The calculated MO diagrams show that $\mathrm{Ni}(\mathrm{DACO}), \mathrm{Ni}(\mathrm{MSE})$ and $\mathrm{Ni}(\mathrm{BSE})$ are $\mathrm{d}^{8}$ sq. planar diamagnetic species (consistent with experiment) with an unoccupied Ni $3 \mathrm{~d}_{x^{2}}-\mathrm{y}^{2}$ LUMO. This orbital has strong $\sigma$ antibonding interactions with $\mathrm{S}_{3 p}$ and $\mathrm{N}_{2 p}$ orbitals in all three complexes. The calculated $\mathrm{S}_{3 \mathrm{p}}$ character of the unoxidized thiolate in the $\mathrm{Ni}_{3 \mathrm{~d}}$ hole is $34 \%$ (two thiolates) and $18 \%$ (one thiolate) in $\mathrm{Ni}(\mathrm{DACO})$ and $\mathrm{Ni}(\mathrm{MSE})$, respectively. The calculated total $\mathrm{S}_{3 \mathrm{p}}$ character for the oxidized thiolates is $18 \%$ (summed over $\alpha$ and $\beta$ holes) in $\mathrm{Ni}(\mathrm{BSE})$. These calculated values are in reasonable agreement with the experimental data obtained on $\mathrm{Ni}$ (DACO) (46\%), Ni(MSE) (25\%, only thiolate) and Ni(BSE) (18\%) (Table 1). ${ }^{44}$

The total $\mathrm{Ni}_{3 \mathrm{~d}}$ character in $\mathrm{Ni}(\mathrm{DACO})$ and $\mathrm{Ni}(\mathrm{BSE})$ are $47 \%$ and $40 \%$ in the acceptor

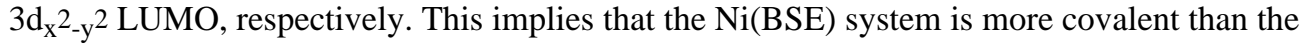
$\mathrm{Ni}(\mathrm{DACO})$ system which is not consistent with the idea that an oxidized $\mathrm{RSO}_{2}{ }^{-}$ligand is a poorer donor than a $\mathrm{RS}^{-}$ligand. The calculated $\% \mathrm{~S}_{3 p}$ character in the LUMO decreases from $36 \%$ in $\mathrm{Ni}$ (DACO) to $18 \%$ in $\mathrm{Ni}(\mathrm{BSE})$ consistent with the experimental data (Table 1).

However the decrease in the calculated $\mathrm{Ni}_{3 \mathrm{~d}}$ and $\mathrm{S}_{3 \mathrm{p}}$ characters from $\mathrm{Ni}$ (DACO) to $\mathrm{Ni}(\mathrm{BSE})$ is associated with an increase in the $\mathrm{O}_{2 \mathrm{p}}$ character in the $\mathrm{RSO}_{2}{ }^{-}$fragment in the LUMO (Fig. 3). Thus the total $\mathrm{RSO}_{2}^{-}$ligand contribution to the $3 \mathrm{~d}_{\mathrm{x}}{ }^{2}-\mathrm{y}^{2}$ LUMO is $42 \%$ in $\mathrm{Ni}(\mathrm{BSE})$, which explains its higher covalency relative to $\mathrm{Ni}(\mathrm{DACO})\left(36 \% \mathrm{RS}^{-}\right.$character in the LUMO). The mixing of the $\mathrm{O}_{2 \mathrm{p}}$ character into the $\mathrm{Ni}_{3 \mathrm{~d}}$ LUMO indicates that the donor orbitals in the BSE ligand is delocalized over the $\mathrm{RSO}_{2}^{-}$fragment.

DFT calculations were performed on free ligands to analyze the mixing of $\mathrm{O}_{2 p}$ in the LUMO of $\mathrm{Ni}(\mathrm{BSE})$. These calculations show (Scheme 1) that the $\mathrm{RSO}_{2}{ }^{-}$ligand has valence orbitals that are delocalized over the $\mathrm{SO}_{2}{ }^{-}$unit available for bonding. The thiolate $\mathrm{S}$ valence orbital which will $\pi$ donate to a metal interacts with one $\mathrm{O}_{2 p}$ orbital on each of the two $\mathrm{O}$ atoms in $\mathrm{RSO}_{2}{ }^{-}$to form a S-O $\sigma$ bonding, an $\mathrm{O}_{2 \mathrm{p}}$ based non-bonding and a S-O $\sigma^{*}$ antibonding orbital. The orbital of the thiolate which would $\sigma$ donate to the metal likewise interacts with two $\mathrm{O}_{2 p}$ orbitals (one from each oxygen atom of $\mathrm{RSO}_{2}{ }^{-}$) to form a S-O $\pi$ bonding, an $\mathrm{O}_{2 \mathrm{p}}$ based nonbonding and a S-O $\pi^{*}$ antibonding orbital. Out of these six $\mathrm{RSO}_{2}{ }^{-} \mathrm{MOs}$ the $\mathrm{S}-\mathrm{O} \sigma$ and $\pi$ bonding orbitals are occupied and stabilized in energy such that they can not efficiently interact with the metal. The $\mathrm{S}-\mathrm{O} \sigma^{*}$ orbital is unoccupied, thus doesn't donate to the metal. Note that we are ignoring the possibility that $\mathrm{O}_{2 \mathrm{p}}$ based non-bonding orbital can serve as donor orbital as they are not directly co-ordinated to the metal. The only possible donor interaction is with the S$\mathrm{O} \pi^{*}$ antibonding orbital which is occupied, at higher energy relative to a thiolate (owing to its $\pi^{*}$ nature) and is oriented along the S-M bond and thus can form a covalent $\sigma$ bond with the metal center.

The covalency of a metal-ligand bond is directly proportional to the overlap $\left(\mathrm{H}_{\mathrm{ML}}\right)$ and inversely proportional to the energy separation between the metal acceptor and the ligand donor orbital $(\Delta)$ before bonding. The $\mathrm{H}_{\mathrm{ML}}$ term favors the $\mathrm{RS}^{-}$ligand due to there being $80 \% \mathrm{~S}_{3 p}$ character in the $\mathrm{RS}^{-}$donor orbital relative to $35 \% \mathrm{~S}_{3 \mathrm{p}}$ in $\mathrm{RSO}_{2}{ }^{-}$(S atom coordinated in both cases). However the relative energies of these donor orbitals are affected by the oxidation state of the $\mathrm{S}$ atom, the $\pi$-antibonding nature of the $\mathrm{RSO}_{2}{ }^{-}$donor orbital, and by Coulombic interaction with the positively charged $\mathrm{Ni}^{\mathrm{II}}$ center. The formal oxidation states of the $\mathrm{S}$ 's are +2 and -2 and the charges on the S's in the calculations are +0.7 and -0.8 for $\mathrm{RSO}_{2}{ }^{-}$and $\mathrm{RS}^{-}$, respectively. The higher oxidation state of $\mathrm{S}$ in $\mathrm{RSO}_{2}{ }^{-}$will tend to stabilize this donor 
orbital while the higher positive charge on the $\mathrm{S}$ atom in $\mathrm{RSO}_{2}{ }^{-}$will destabilize it relative to the donor orbitals of a $\mathrm{RS}^{-}$ligand upon interaction with the positively charged Ni. Additionally the $\pi$-antibonding nature of the $\mathrm{RSO}_{2}{ }^{-}$donor orbital raises its energy relative to a $\mathrm{S}_{3 \mathrm{p}}$ based $\mathrm{RS}^{-}$donor orbital. The resultant donor orbital descriptions (including the effect of Ni charge) and their relative energies are shown in Fig. 4. The delocalized $\mathrm{RSO}_{2}{ }^{-}$donor orbital (Fig. 4, left), with only $35 \% \mathrm{~S}_{3 \mathrm{p}}$, is $2.5 \mathrm{eV}$ higher in energy than the mainly $\mathrm{S}_{3 \mathrm{p}}$ based $\mathrm{RS}^{-}$donor orbital ( with $80 \% \mathrm{~S}_{3 \mathrm{p}}$ ). Thus while the overlap will be less due to the reduced $\mathrm{S}$ character, the favorable energies of the donor orbital of $\mathrm{RSO}_{2}{ }^{-}$results in a very covalent interaction with the metal as observed in the experimental data and the calculations. Also the $\mathrm{RSO}_{2}{ }^{-}$ligand has a shorter $\mathrm{Ni}$-S distances (2.13 $\AA$ in $\mathrm{Ni}(\mathrm{BSE})$ relative to $2.17 \AA$ in $\mathrm{Ni}$ (DACO)) which reflects its observed net higher covalency.

\section{Ni-S bond length}

The crystallographically obtained Ni-S bond length in Ni(BSE) is $2.13 \AA$, which is $0.04 \AA$ shorter than the Ni-S bond distances in the Ni(DACO) dithiolate. Several possible factors could contribute to the shortening of the Ni-S bonds with an oxidized $\mathrm{RSO}_{2}{ }^{-}$donor: 1) Constraints of the ligand framework, 2) Increased ionic interaction of the $\mathrm{Ni}^{\mathrm{iI}}$ with the oxygens in the $\mathrm{RSO}_{2}{ }^{-}$ligand, and 3) decreased electron repulsion between the $\mathrm{Ni}_{3 \mathrm{~d}}$ and the non-bonding $\pi$ donor $\mathrm{S}_{3 \mathrm{p}}$ orbitals of a thiolate upon oxidation. ${ }^{18}$ To evaluate the effect of the macrocyclic ligand, geometry optimizations of simpler systems $\left[\mathrm{NiF}_{3} \mathrm{X}\right]^{2-}$ (where $\mathrm{X}=\mathrm{RS}^{-}$or $\mathrm{RSO}_{2}^{-}$) were performed. These calculations reproduce (Fig. 5) the Ni-S bond shortening in $\mathrm{RSO}_{2}{ }^{-}(2.09 \AA)$ relative to $\mathrm{RS}^{-}\left(2.25 \AA\right.$ ). Also the calculated charge (NPA) on the $\mathrm{S}$ atom in the $\mathrm{RSO}_{2}{ }^{-}$is estimated to be +0.7 relative to -0.8 in $\mathrm{RS}^{-}$, which disfavors $\mathrm{Ni}-\mathrm{S}$ bond shortening in the former due to its increased electrostatic repulsion. These results imply that the primary contribution to the Ni-S bond shortening in $\mathrm{RSO}_{2}{ }^{-}$may be reduction of e-e repulsion between the filled $\mathrm{Ni}_{3 \mathrm{~d}}$ (mainly $\mathrm{xz}, \mathrm{yz}$ ) and out of plane $\mathrm{S}_{3 \mathrm{p}}$ orbitals. This repulsion energy between the $\mathrm{Ni}^{2+}$ and the ligand fragments was calculated using the Pauli repulsion term in the Zeigler energy decomposition scheme available in the ADF package. ${ }^{33,45}$ In Ni(BSE) a decrease in the Ni$\mathrm{S}$ bond length from $2.17 \AA$ (observed in the thiolates) to the optimized $2.13 \AA$, leads to an increase in the filled-filled repulsion by $1.07 \mathrm{eV}$. The associated increase in bonding interactions compensate for this. Alternatively in $\mathrm{Ni}(\mathrm{DACO})$ the same contraction of the $\mathrm{Ni}$ $\mathrm{S}$ bond length leads to a $4.29 \mathrm{eV}$ increase in the filled-filled repulsion which is not compensated by an increase in bonding. Thus oxidation of $\mathrm{RS}^{-}$results in stabilization of the out-of-plane non-bonding $\mathrm{S}_{3 \mathrm{p}}$ orbital due to formation of a S-O $\sigma$ bond which reduces the interaction of this electron pair with the filled $\mathrm{Ni}_{3 \mathrm{~d}}$ orbitals. ${ }^{46}$ Though this filled-filled interaction does not affect the covalent contribution to the Ni-S bond energy, it manifests itself in the nature of the HOMO in these complexes. The HOMO in $\mathrm{Ni}(\mathrm{DACO})$ is the $\mathrm{d}_{\mathrm{xz}}$ orbital, which has a very strong $\pi$ antibonding interaction with the out-of-plane $\mathrm{S}_{3 p}$ donor orbitals. In Ni(BSE) this orbital is stabilized as it lacks this $\pi$ antibonding interaction with the out-of-plane $S_{3 p}$ orbital and the $\mathrm{d}_{\mathrm{z}^{2}}$ orbital is the HOMO (Fig. 3).

\section{Discussion}

The experimental and computational results on the $\mathrm{Ni}^{\mathrm{II}}$ series in Fig. 1 provide evidence that oxidized $\mathrm{RSO}_{2}{ }^{-}$ligands are in fact strong $\sigma$ donors. This derives from the higher energies of the oxidized S-O $\pi^{*}$ orbital which acts as the $\sigma$ donor to the metal center. This higher energy is due to the $\pi^{*}$ nature of the orbital and the positive charge on the $S$ which is destabilized upon electrostatic interaction with the Ni. However in contrast to $\mathrm{RS}^{-}, \mathrm{RSO}_{2}{ }^{-}$ligands are not involved in $\pi$ donation as this $S_{3 p}$ orbital is stabilized and localized due to formation of strong $\mathrm{S}-\mathrm{O} \sigma$ bonds. 
The S K-edge XAS data in the mixed ligand complex Ni(MSE) show that the Ni-S covalency of the unoxidized thiolate remains unchanged upon oxidation of the adjacent thiolate donor. This spectator effect supports the idea that the oxidized $\mathrm{RSO}_{2}{ }^{-}$is still a strong $\sigma$ donor and needs no compensation in a $\sigma$ bonding only system like sq. planar $\mathrm{Ni}^{\mathrm{II}}$. That is, the oxidation of one thiolate to $\mathrm{RSO}_{2}{ }^{-}$does not induce additional electron donation from the unmodified thiolate.

The lack of a compensatory effect in the nickel thiolate/sulfinate complex is in contrast to the results obtained on a low-spin $\mathrm{Fe}^{\mathrm{III}}$ system where experimental data indicated that modification of a thiolate to $\mathrm{RSO}^{-}$decreased its net charge donation to the $\mathrm{Fe}^{\mathrm{III}}$. ${ }^{28}$ An unoxidized thiolate spectator ligand, in turn, became a much stronger donor which compensated for the loss of charge donation from the oxidized thiolate. The different behavior in these two systems (low spin $\mathrm{Fe}^{\mathrm{III}}$ and $\mathrm{Ni}^{\mathrm{II}}$ ) arises from the difference in bonding interactions of these metals with the thiolate based ligands. In low-spin $\mathrm{Fe}^{\mathrm{III}}$ both $\pi$ and $\sigma$ donor interactions are present and the $\mathrm{t}_{2}{ }^{5}$ configuration requires that the $\pi$-donor orbitals from the two thiolate ligands compete for the singly occupied $\mathrm{d}-\pi$ molecular orbital (SOMO) for bonding. Thus oxidizing a thiolate eliminates its $\pi$-donor interaction which reduces the total charge donation from this thiolate and enhances the $\pi$ donation by the unoxidized thiolate. However in the sq. planar $\mathrm{Ni}^{\mathrm{II}}$ system studied here only $\sigma$ interactions are possible. As the oxidized thiolate ligand $\mathrm{RSO}_{2}{ }^{-}$is still a good $\sigma$ donor ligand (using its $\mathrm{S}-\mathrm{O} \pi^{*}$ orbital) there is no decrease in charge donation upon oxidation of the thiolate, hence no increase in charge donation from the unoxidized thiolate is observed. It is interesting to note that if we extend these results computationally to hypothetical $\mathrm{Ni}^{\mathrm{III}}$ complexes, a decrease in total charge donation from $\mathrm{RSO}_{2}{ }^{-}$relative to $\mathrm{RS}^{-}$is now observed. While in $\mathrm{Ni}^{\mathrm{III}}(\mathrm{DACO})$ the $\mathrm{d}-\pi \mathrm{SOMO}$ of $\mathrm{Ni}^{\mathrm{III}}$ has $16 \% \mathrm{~S}_{3 \mathrm{p}}$ on each thiolate, the $\%$ $\mathrm{S}_{3 \mathrm{p}}$ of the oxidized thiolate in the $\mathrm{d}-\pi \mathrm{SOMO}$ of $\mathrm{Ni}^{\mathrm{iII}}(\mathrm{MSE})$ decreases to $0 \%$ and the $\% \mathrm{~S}_{3 \mathrm{p}}$ of the remaining unoxidized thiolate (Fig. S1, Supplementary Information) increases to $50 \%$ as it compensates for the loss of $\pi$ donation from the other thiolate upon oxidation to $\mathrm{RSO}_{2}{ }^{-}$.

The lack of $\pi$ donation by an oxidized thiolate ligand was proposed to result in an increased $6^{\text {th }}$ ligand binding affinity in the oxidized active site of $\mathrm{Fe}^{\mathrm{III}}$ type Nhase. ${ }^{23}$ Our results here suggest that the oxidized thiolates are as strong $\sigma$ donors as the unoxidized thiolates. Thus one may expect some differences in the role played by oxidized thiolates between the low-spin $\mathrm{Fe}^{\mathrm{III}}$ (with both $\pi$ and $\sigma$ interactions in the $\mathrm{t}_{2}{ }^{5}$ configuration) and $\mathrm{Co}^{\mathrm{III}}$ (with only $\sigma$ interaction in the $\mathrm{t}_{2}{ }^{6}$ configuration) Nhases. DFT calculations were used to evaluate these possible differences. The optimized structures of the six coordinate unoxidized (three $\mathrm{RS}^{-}$, two amide donors and $\mathrm{CH}_{3} \mathrm{CN}$, Fig. 6 left) and oxidized (a RS${ }^{-}$, a $\mathrm{RSO}^{-}$, a $\mathrm{RSO}_{2}{ }^{-}$, two amide donors and $\mathrm{CH}_{3} \mathrm{CN}$, Fig. 6 middle) active sites of Nhase were obtained. The Fe $\mathrm{F}^{\mathrm{III}}$ Nhase had optimized Fe- $\mathrm{N}_{\text {axial }} \mathrm{CH}_{3} \mathrm{CN}$ distances of $2.53 \AA$ and $1.99 \AA$ for the unoxidized and the oxidized active site, respectively (Table 3, rows 1 and 2). These results parallel those obtained in Ref. 23 using $\mathrm{H}_{2} \mathrm{O}$ as an axial ligand. In contrast, the calculations for the Co $\mathrm{CIII}^{\mathrm{II}}$ active site of Nhase show that the axial ligand is already strongly bound in the unoxidized active site and there is no significant change in the axial ligand binding affinity for the oxidized active site (optimized Co- $\mathrm{N}_{\text {axial }}$ distances are $1.83 \AA$ and $1.81 \AA$, respectively (Table 3 , rows 3 and 4 )). The binding of the axial ligand in low-spin $\mathrm{Co}^{\mathrm{III}}\left(\mathrm{t}_{2}{ }^{6}\right)$ active site indicates its higher Lewis acidity due to lack of $d-\pi$ donor bonding which is present in the low-spin Fe $\mathrm{III}^{\mathrm{III}}\left(\mathrm{t}_{2}{ }^{5}\right)$ active site (as indicated by the shorter $\mathrm{Fe}-\mathrm{S}_{\text {axial }}$ relative to the $\mathrm{Co}-\mathrm{S}_{\text {axial }}$ distance in the unoxidized active site in Table 3). Upon oxidation of the equatorial thiolates, their $\pi$ donation to the low-spin Fe d- $\pi$ orbital decreases and this increases its Lewis acidity and enhances binding of the axial $\mathrm{CH}_{3} \mathrm{CN}\left(\mathrm{Fe}-\mathrm{N}_{\mathrm{axial}}=1.99\right.$ $\AA$ ). No significant difference in the axial $\mathrm{CH}_{3} \mathrm{CN}$ binding affinity of the on $\sigma$ bonding Co active site is observed upon oxidation of the equatorial thiolates.

This suggests that while the oxidized cysteine ligands likely play a role in tuning the Lewis acidity of the Fe active site, this does not appear to be necessary in the Co active site. The post- 
translational modification of one of the cysteines to $\mathrm{S}^{-} \mathrm{O}^{-}$may play the role of a proton source for this hydrolytic reaction as it is found to be protonated under physiological conditions. ${ }^{13}$ The $\mathrm{SO}_{2}{ }^{-}$ligand may play a role in axial ligand binding by $\mathrm{H}$-bonding and proton shuttling between the axial ligand and nearby arginine residues (Fig. 6, right) as suggested by mutational studies 12 .

\section{Supplementary Material}

Refer to Web version on PubMed Central for supplementary material.

\section{ACKNOWLEDGMENT}

This research was supported by NIH Grants 0446304 (E.I.S.), RR-01209 (K.O.H.), NSF CHE 06-11695 (M.Y.D.). SSRL operations are supported by the Department of Energy, Office of Basic Energy Sciences. The SSRL Structural Molecular Biology Program is supported by the National Institutes of Health, National Center for Research Resources, Biomedical Technology Program, and by the Department of Energy, Office of Biological and Environmental Research.

\section{References}

1. Nagashima SNM, Dohmae N, Tsujimura M, Takio K, Odaka M, Yohda M, Kamiya N, Endo I. Nature Structural Biology 1998;5:347-351.

2. Miyanaga A, Fushinobu S, Ito K, Wakagi T. Biochemical and Biophysical Research Communications 2001;288:1169-1174. [PubMed: 11700034]

3. Endo I, Nojiri M, Tsujimura M, Nakasako M, Nagashima S, Yohda M, Odaka M. Journal of Inorganic Biochemistry 2001;83:247-253. [PubMed: 11293544]

4. Nojiri M, Yohda M, Odaka M, Matsushita Y, Tsujimura M, Yoshida T, Dohmae N, Takio K, Endo I. Journal of Biochemistry (Tokyo) 1999;125:696-704.

5. Murakami T, Nojiri M, Nakayama H, Odaka M, Yohda M, Dohmae N, Takio K, Nagamune T, Endo I. Protein Science 2000;9:1024-1030. [PubMed: 10850812]

6. Shearer J, Kung IY, Lovell S, Kaminsky W, Kovacs JA. Journal of the American Chemical Society 2001;123:463-468. [PubMed: 11456548]

7. Mascharak PK. Coordination Chemistry Reviews 2002;225:201-214.

8. Greene SN, Richards NGJ. Inorganic Chemistry 2004;43:7030-7041. [PubMed: 15500340]

9. Kovacs JA. Chemical Reviews 2004;104:825-848. [PubMed: 14871143]

10. Nagashima S, Nakasako M, Dohmae N, Tsujimura M, Takio K, Odaka M, Yohda M, Kamiya N, Endo I. Nature Structural Biology 1998;5:347-351.

11. Miyanaga A, Fushinobu S, Ito K, Shoun H, Wakagi T. European Journal of Biochemistry 2004;271:429-438. [PubMed: 14717710]

12. Piersma SR, Nojiri M, Tsujimura M, Noguchi T, Odaka M, Yohda M, Inoue Y, Endo I. Journal of Inorganic Biochemistry 2000;80:283-288. [PubMed: 11001100]

13. Dey A, Chow M, Taniguchi K, Lugo-Mas P, Davin S, Maeda M, Kovacs JA, Odaka M, Hodgson KO, Hedman B, Solomon EI. Journal of the American Chemical Society 2006;128:533-541. [PubMed: 16402841]

14. Boone AJ, Chang CH, Greene SN, Herz T, Richards NGJ. Coordination Chemistry Reviews 2003;238:291-314.

15. Harrop TC, Mascharak PK. Accounts of Chemical Research 2004;37:253-260. [PubMed: 15096062]

16. Darensbourg MY, Font I, Mills DK, Pala M, Reibenspies JH. Inorganic Chemistry 1992;31:49654971.

17. Farmer PJ, Reibenspies JH, Lindahl PA, Darensbourg MY. Journal of the American Chemical Society 1993;115:4665-4674.

18. Bellefeuille JA, Grapperhaus CA, Buonomo RM, Reibenspies JH, Darensbourg MY. Organometallics 1998;17:4813-4821.

19. Chohan BS, Maroney MJ. Inorg. Chem 2006;45:1906-1908. [PubMed: 16499349]

Inorg Chem. Author manuscript; available in PMC 2008 October 9. 
20. Chohan BS, Shoner SC, Kovacs JA, Maroney MJ. Inorganic Chemistry 2004;43:7726-7734. [PubMed: 15554637]

21. Tyler LA, Noveron JC, Olmstead MM, Mascharak PK. Inorganic Chemistry 2000;39:357-362. [PubMed: 11272547]

22. Glaser T, Hedman B, Hodgson KO, Solomon EI. Accounts of Chemical Research 2000;33:859-868. [PubMed: 11123885]

23. Solomon EI, Hedman B, Hodgson KO, Dey A, Szilagyi RK. Coordination Chemistry Reviews 2005;249:97-129.

24. Shadle SE, Hedman B, Hodgson KO, Solomon EI. Inorganic Chemistry 1994;33:4235-4244.

25. Neese F, Hedman B, Hodgson KO, Solomon EI. Inorganic Chemistry 1999;38:4854-4860. [PubMed: 11671216]

26. Shadle SE, Penner-Hahn JE, Schugar HJ, Hedman B, Hodgson KO, Solomon EI. J. Am. Chem. Soc 1993;115:767-776.

27. Hedman B, Frank P, Gheller SF, Roe AL, Newton WE, Hodgson KO. Journal of the American Chemical Society 1988;110:3798-3805.

28. Lugo-Mas P, Dey A, Xu L, Davin SD, Benedict J, Kaminsky W, Hodgson KO, Hedman B, Solomon EI, Kovacs JA. J. Am. Chem. Soc 2006;128:11211-11221. [PubMed: 16925440]

29. Farmer PJ, Solouki T, Mills DK, Soma T, Russell DH, Reibenspies JH, Darensbourg MY. Journal of the American Chemical Society 1992;114:4601-4605.

30. George, GN. EXAFSPAK \& EDG_FIT; Stanford Synchrotron Radiation Laboratory, Stanford Linear Accelerator Center. Stanford, CA: Stanford University; 2000.

31. Agarwal, B. X-ray Spectroscopy. Berlin: Springer-Verlag; 1979. p. $276 \mathrm{ff}$

32. Tyson TA, Roe AL, Frank P, Hodgson KO, Hedman B. Physical Review B 1989;39:6305-6315.

33. Baerends EJ, Ellis DE, Ros P. Chemical Physics 1973;2:41-51.

34. Vosko SH, Wilk L, Nusair M. Canadian Journal of Physics 1980;58:1200-1211.

35. Becke AD. Journal of Chemical Physics 1993;98:5648-5652.

36. Perdew JP. Physical Review B (Condensed Matter) 1986;33:8822-8824.

37. Frisch M, et al. Full reference in Supplementary Information.

38. Becke AD. Physical Review A 1988;38:3098-3100. [PubMed: 9900728]

39. Mulliken RS. Journal of Chemical Physics 1955;23:1833-1840.

40. Tenderholt, AL. PyMOlyze, Version 1.1. http://pymolyze.sourceforge.net.

41. Sarangi R, George DeBeer S, Rudd DJ, Szilagyi RK, Ribas X, Rovira C, Almeida M, Hodgson KO, Hedman B, Solomon EI. J. Am. Chem. Soc 2007;129

42. Szilagyi RK, Lim BS, Glaser T, Holm RH, Hedman B, Hodgson KO, Solomon EI. Journal of the American Chemical Society 2003;125:9158-9169. [PubMed: 15369373]

43. Note that the intensity of the rising edge-of a $\mathrm{RSO}_{2}{ }^{-}$is $4-5$ times that of a thiolate. This increase partially reflects the fact that there is more $\% \mathrm{~S}_{3 \mathrm{p}}$ in the acceptor orbitals in $\mathrm{RSO}_{2}{ }^{-}$(calculated $130 \%$ ) due to the additional S-O $\sigma^{*}$ orbitals relative to a thiolate ligand (calculated $60 \%$ ) along with the 2.25 fold increase in the transition moment integral.

44. Note that the experimentally obtained Ni-S covalency is higher than the calculated value. This is commonly observed at this level of theory. This can also have some contribution form a $0.01 \AA$ longer $\mathrm{Ni}-\mathrm{S}$ bond in the optimized structures.

45. te Velde G, Bickelhaupt FM, van Gisbergen SJA, Fonseca Guerra C, Baerends EJ, Snijders JG, Ziegler T. Journal of Computational Chemistry 2001;22:931-967.

46. A single point calculation of $\mathrm{NiF}_{3} \mathrm{RSO}_{2}$ with the $\mathrm{Ni}-\mathrm{S}$ bond length fixed at $2.25 \AA$ (i.e. bond length of a $\mathrm{Ni}-\mathrm{SR}$ bond) shows that even at a longer $\mathrm{Ni}-\mathrm{S}$ distance this system is very covalent $(\% \mathrm{Ni} 3 \mathrm{~d}=$ $62 \%$ ) which provides a driving force for the bond shortening once the e-e repulsion along the Ni-S bond is reduced upon oxidation. 

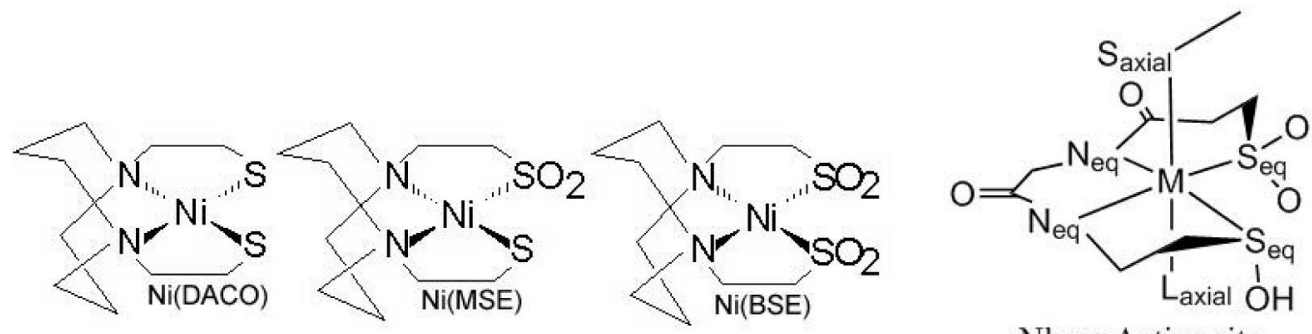

Nhase Active site

Figure 1.

Schematic diagram of the model complexes used in this study. From left: Ni(DACO), Ni(MSE), $\mathrm{Ni}(\mathrm{BSE})$ and the active site of Nhase. 


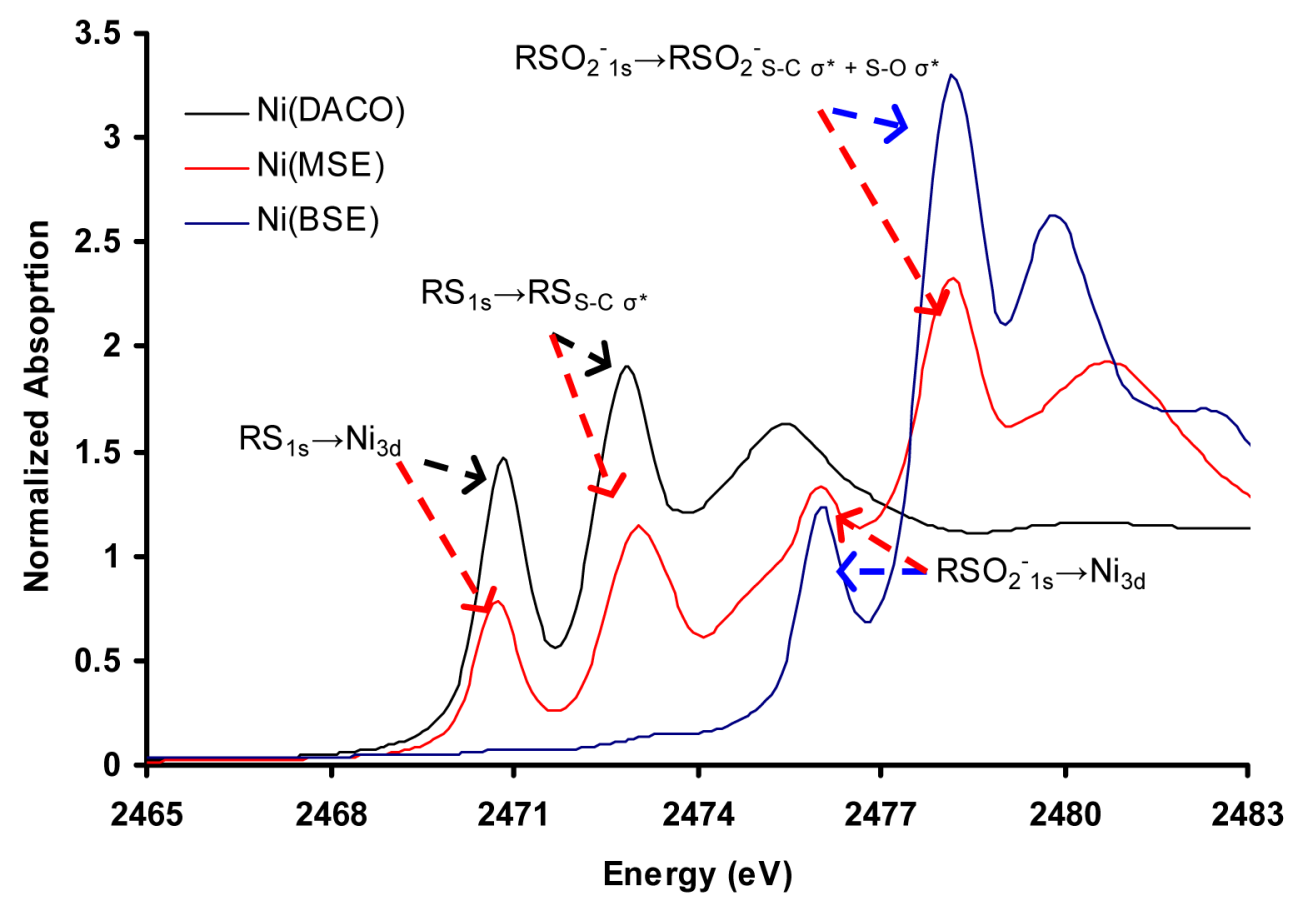

Figure 2.

$\mathrm{S}$ K-edge XAS data of Ni(DACO) (black), Ni(MSE) (red) and Ni(BSE) (blue). The relevant pre-edge and rising edge transitions are labeled. For assignments of these features see Reference 23. 


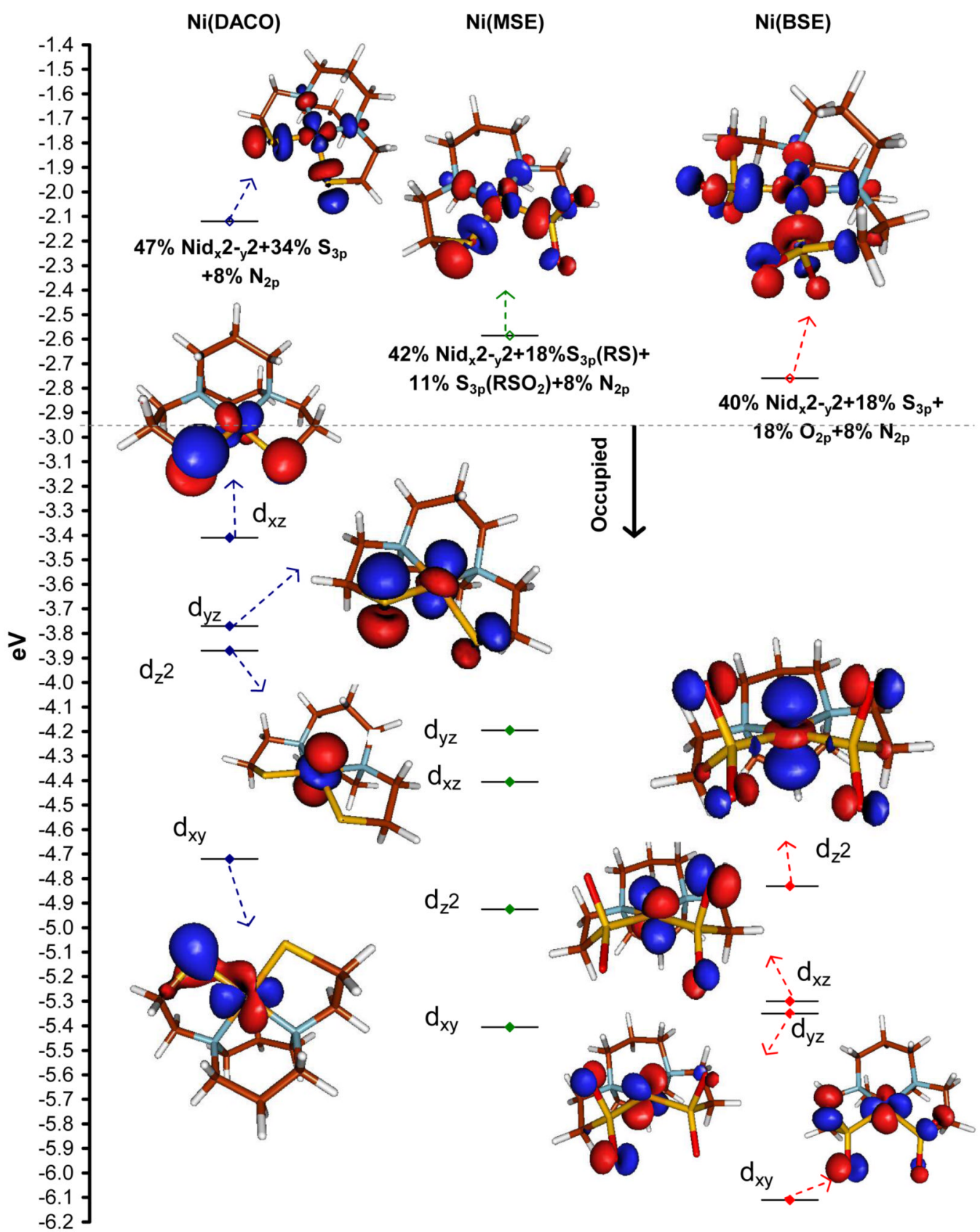

Figure 3.

MO diagram of the complexes $\mathrm{Ni}(\mathrm{BSE}), \mathrm{Ni}(\mathrm{MSE})$ and $\mathrm{Ni}(\mathrm{DACO})$. The relevant $\mathrm{Ni}_{3 \mathrm{~d}}$ contours are shown (occupied orbitals are indicated by filled diamonds). The contours of Ni(MSE) are similar to that of $\mathrm{Ni}(\mathrm{BSE})$ and hence they are not shown to avoid crowding. The $\mathrm{Ni}_{3 \mathrm{~d}}, \mathrm{~S}_{3 \mathrm{p}}$, $\mathrm{O}_{2 \mathrm{p}}$ and $\mathrm{N}_{2 \mathrm{p}}$ coefficients are indicated in text. Orbitals above the dashed lines are unoccupied. 


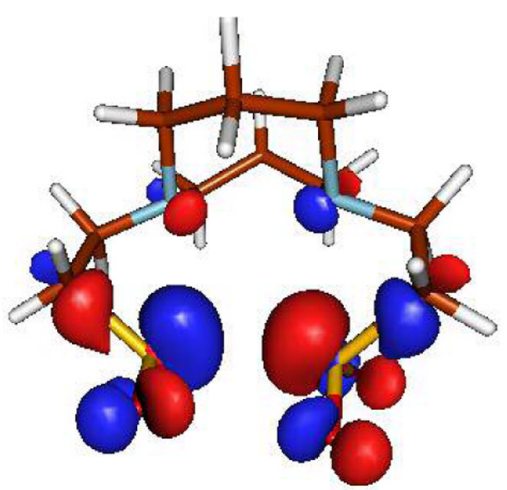

$E=+2.45 \mathrm{eV}$

$72 \% \mathrm{SO}_{2}\left(35 \% \mathrm{~S}_{3 p}, 12 \% \mathrm{~S}_{3 \mathrm{~s}}\right)$

$q_{s}=0.70, q_{o}=-0.53$

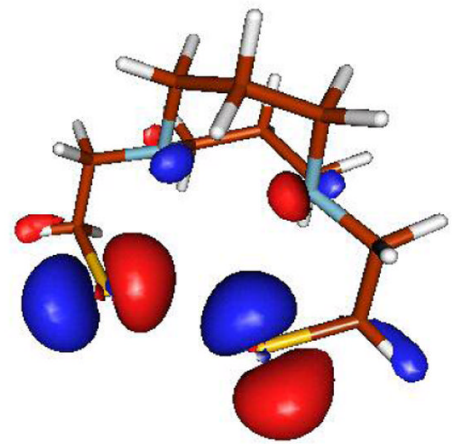

$\mathrm{E}=0.0 \mathrm{eV}$

$85 \% \operatorname{RS}\left(80 \% \mathrm{~S}_{3 p}\right)$

$$
q_{s}=-0.8
$$

Figure 4.

The donor valence orbitals of the $\mathrm{RSO}_{2}{ }^{-}$and the $\mathrm{RS}^{-}$ligand including the effect of the charge of a central Ni atom (modeled as a point charge). 


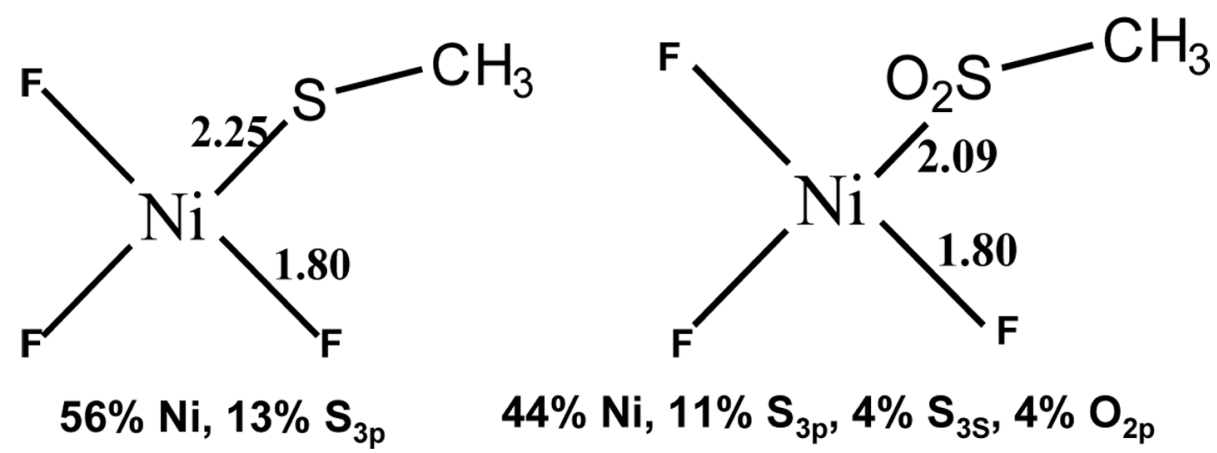

Figure 5.

Geometry optimized parameters of $\mathrm{NiF}_{3} \mathrm{X}\left(\mathrm{X}=\mathrm{RS}^{-}\right.$in left and $\mathrm{RSO}_{2}{ }^{-}$in right $)$systems. 

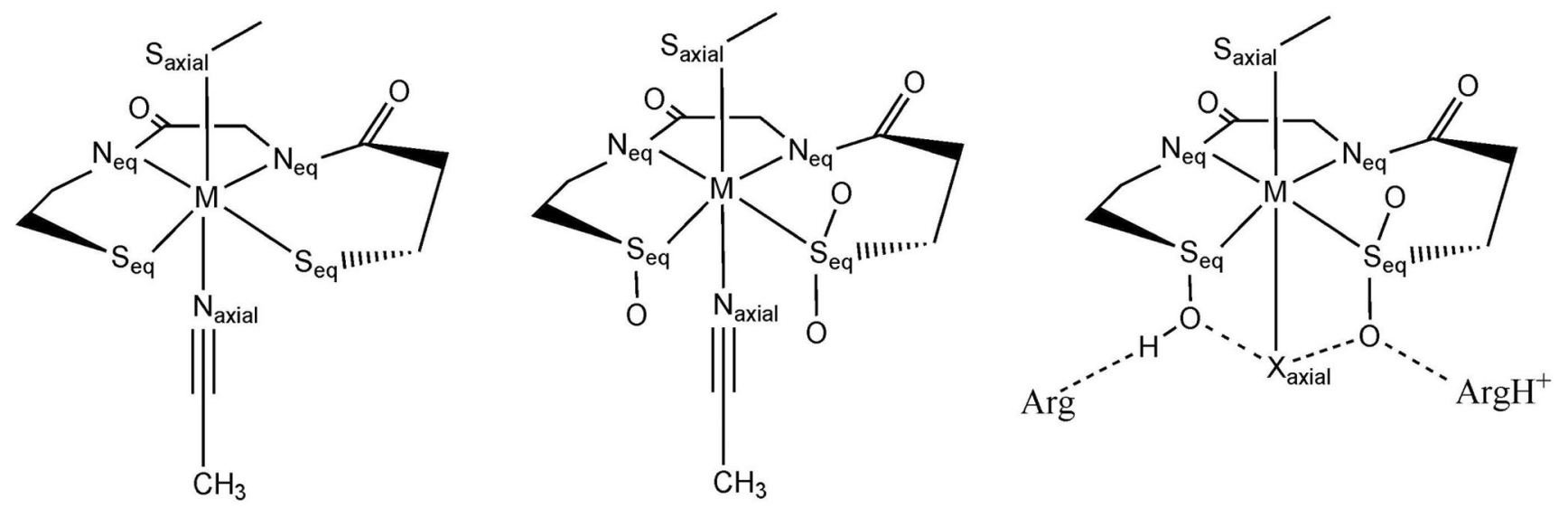

Figure 6.

Models $\mathrm{CH}_{3} \mathrm{CN}$ bound forms of the oxidized (middle) and unoxidized (left) and the H-bonding interaction in the modified active site (right) of Nhase. 


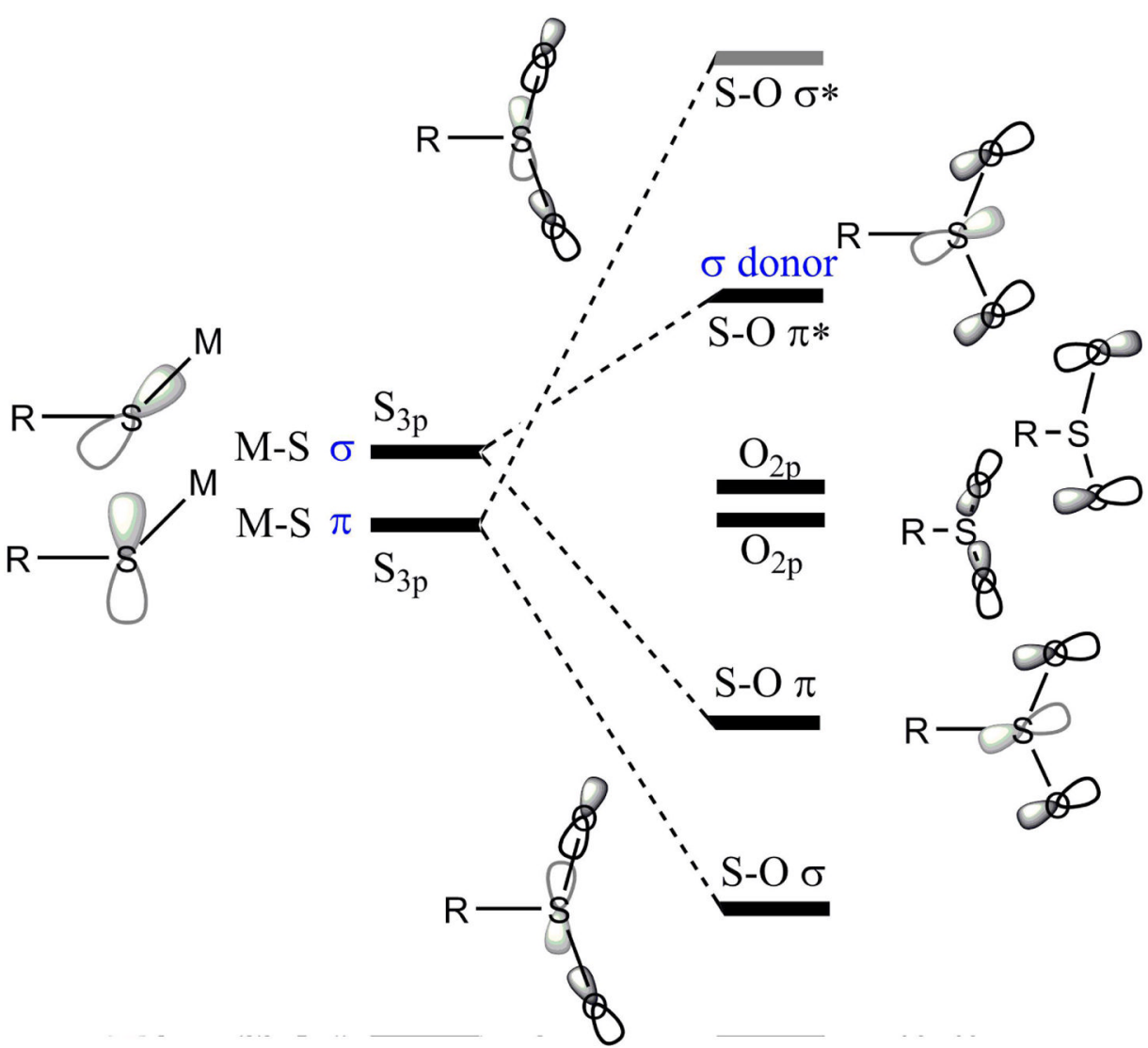

Scheme 1.

Schematic MO diagram of an $\mathrm{RSO}_{2}{ }^{-}$fragment (right) correlated to parent $\mathrm{RS}^{-} \mathrm{MOs}$ (left). The nature of the MO's and the type of donor interaction of an orbital with a metal center are indicated. Only four $\mathrm{O}_{2 \mathrm{p}}$ orbitals (two each on $\mathrm{SO}_{2}{ }^{-}$oxygen) that interact with the $\mathrm{S}_{3 \mathrm{p}}$ are shown in this scheme. The third set of the $\mathrm{O}_{2 p}$ is non-bonding. The MO's indicated by black lines are occupied and the one indicated by a grey line is unoccupied. 


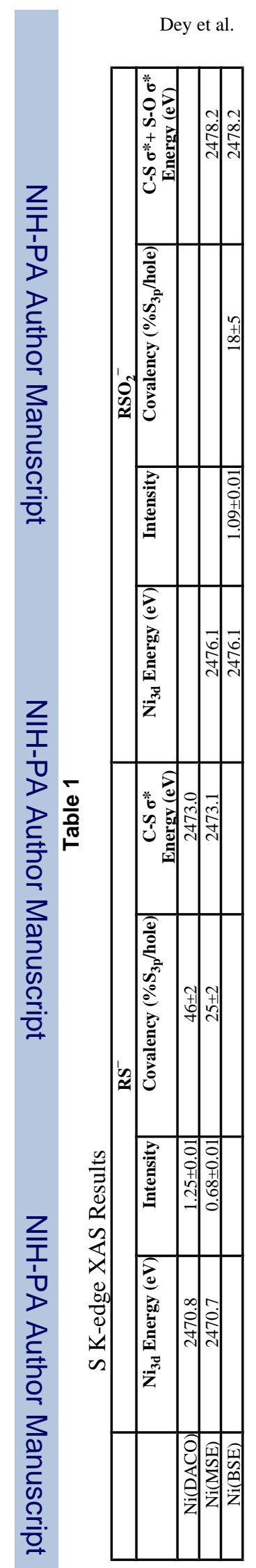

Inorg Chem. Author manuscript; available in PMC 2008 October 9. 


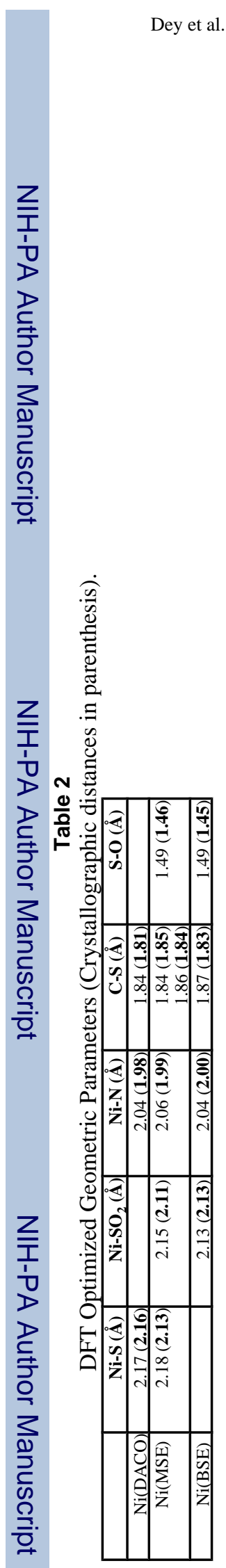

Inorg Chem. Author manuscript; available in PMC 2008 October 9. 
Table 3

DFT optimized distances $(\AA)$ of oxidized and unoxidized Fe and Co type Nhase

\begin{tabular}{|c|c|r|r|r|}
\hline Model & $\mathbf{M}_{\mathbf{a x i a}}$ & $\mathbf{M}_{\mathbf{e q}}$ & $\mathbf{M}_{\mathbf{e q}}$ & $\mathbf{M}_{\mathbf{e q}}$ \\
\hline Fe unoxidized & 2.22 & $2.30,2.31$ & $1.96,2.00$ & 2.53 \\
\hline Fe oxidized & 2.25 & $2.24,2.25$ & $1.96,1.97$ & 1.99 \\
\hline Co unoxidized & 2.35 & $2.35,2.36$ & 1.93 .1 .97 & 1.83 \\
\hline Co oxidized & 2.33 & $2.33,2.25$ & $1.94,2.00$ & 1.81 \\
\hline
\end{tabular}

